\title{
PET Imaging During Radiotherapy of Head and Neck Cancer
}

$\mathbf{T}$ he worldwide incidence of head and neck cancer is estimated at approximately 643,000 (1). In the United States, approximately 53,640 new head and neck cancers will be diagnosed in 2013, with 11,520 deaths expected (2). The treatment choice for head and neck cancer depends on the primary site and surgical resectability; however, with an increasing effort of preservation of organ function the use of definitive radiation therapy alone or in combination with chemotherapy has been increasing, particularly in oropharyngeal cancers. PET/CT with ${ }^{18}$ F-FDG has an established role in initial staging and after completion of radiotherapy to evaluate for the need for salvage surgery. According to guidelines of the National Comprehensive Cancer Network (NCCN), salvage surgery is not necessary

\section{See page 532}

if the posttherapy ${ }^{18} \mathrm{~F}$-FDG $\mathrm{PET} / \mathrm{CT}$ scan result (obtained at least $12 \mathrm{wk}$ after treatment completion) is negative for residual disease and residual nodes are less than $1 \mathrm{~cm}$, whereas surgery is recommended with a positive ${ }^{18} \mathrm{~F}$ FDG PET/CT scan result and residual nodes larger than $1 \mathrm{~cm}$ (3). There are, however, limited data on ${ }^{18} \mathrm{~F}-\mathrm{FDG}$ PET in monitoring treatment response to chemoradiation during treatment, which could allow the early identification of nonresponders who may be candidates for adaptive treatment

Received Feb. 25, 2013; revision accepted Feb. 28, 2013.

For correspondence or reprints contact: Yusuf Menda, Department of Radiology, University of lowa, 200 Hawkins Dr., 3858 JPP lowa City, lowa, 52246.

E-mail: yusuf-menda@uiowa.edu

Published online Mar. 15, 2013.

COPYRIGHT (C) 2013 by the Society of Nuclear

Medicine and Molecular Imaging, Inc.

DOI: 10.2967/jnumed.112.114561 strategies. Brun et al. imaged 47 head and neck cancer patients with ${ }^{18} \mathrm{~F}$ FDG PET at baseline and after a median of $24 \mathrm{~Gy}$ of radiation therapy and found a significantly higher rate of complete remission and better 5-y overall survival in patients with tumors that showed a lower metabolic rate on the mid-therapy scan (4). In a more recent study, Hentschel et al. imaged 37 head and neck cancer patients, one group after 10, 30, and $50 \mathrm{~Gy}$ of radiation and another group after 20,40 , and $60 \mathrm{~Gy}$ of a total of 72 Gy (5). Patients with a rapid drop in ${ }^{18} \mathrm{~F}$-FDG uptake in tumors showed significantly better disease-free survival. Imaging at 10-20 Gy (1-2 wk into radiation therapy) was found to be the best time point for using ${ }^{18} \mathrm{~F}$ FDG PET to monitor patients during therapy (5). The performance of ${ }^{18} \mathrm{~F}$ FDG PET was, however, significantly lower in predicting disease-free survival in 2 additional studies when ${ }^{18}$ F-FDG PET was performed later, after 40 or 47 Gy of radiation, and images were analyzed only visually for the presence or absence of residual uptake in tumors $(6,7)$. It has also been questioned whether the changes in standardized uptake value (SUV) early after radiation therapy fully reflect the changes in the biology of head and neck cancer. In a preclinical study that used autoradiography and PET imaging $11 \mathrm{~d}$ after radiation therapy, the maximum SUV (SUVmax) remained constant, although the tumor ${ }^{18} \mathrm{~F}-\mathrm{FDG}$ accumulation on autoradiography decreased in viable tumor areas (8).

Because both radiation therapy and chemotherapy decrease proliferation rates in responding tumors, imaging the changes in cell proliferation may provide a more accurate evaluation of the treatment effects. Among several radiolabeled nucleoside analogs developed for imaging cell proliferation, $3^{\prime}$-deoxy-3' $-{ }^{18} \mathrm{~F}$-fluorothymidine $\left({ }^{18} \mathrm{~F}\right.$ FLT), a thymidine analog that is not incorporated into DNA, is most widely studied. The intracellular trapping of ${ }^{18} \mathrm{~F}$-FLT is a function of the enzymatic activity of thymidine kinase 1, a key enzyme in DNA synthesis with high activity during the proliferative $S$ phase of the cell cycle and low activity in the quiescent G0/G1 phase (9). Untreated head and neck squamous cell cancers are readily detectable with ${ }^{18} \mathrm{~F}$-FLT PET, with high tumor-to-background ratios, although the SUV with ${ }^{18}$ F-FLT tends to be generally lower than with ${ }^{18}$ F-FDG (10-14). Comparison studies of ${ }^{18} \mathrm{~F}$-FLT and ${ }^{18} \mathrm{~F}$-FDG by Hoshikawa et al. showed similar detectability and false-positive rates in primary tumors and cervical nodal metastases for ${ }^{18} \mathrm{~F}$ FLT and ${ }^{18} \mathrm{~F}$-FDG $(11,12)$. The pretherapy staging of head and neck cancer with ${ }^{18}$ F-FLT PET appears limited by the nontumoral uptake in reactive cervical nodes due to proliferation of reactive B-lymphocytes (15).

Previous studies have shown a significant drop in ${ }^{18} \mathrm{~F}$-FLT uptake in squamous cell head and neck cancer early after initiation of radiotherapy $(14,16)$. However, the correlation between the change in ${ }^{18} \mathrm{~F}$-FLT uptake in head and neck cancer and disease-free survival was only recently reported in 2 studies published in The Journal of Nuclear Medicine $(6,17)$. Hoeben et al. imaged 48 patients with stage III or IV head and neck cancer at 3 time points, first at baseline (pretherapy), after 5-12 daily fractions of radiotherapy (corresponding to 10-24 Gy), and in a subgroup of 29 patients also after 15-19 daily fractions (corresponding to 3038 Gy) (17). Although $98 \%$ of patients had complete clinical response at the end of treatment, the 3-y disease-free survival was only $79 \%$. There was a significantly better disease-free survival in patients who showed a $45 \%$ or more 
drop in SUVmax (and $\geq 41 \%$ on gross tumor volume delineated with ${ }^{18}$ F-FLT) on the early mid-therapy scan. However, the change in SUVmax between the baseline and late mid-therapy scan was not predictive of treatment outcome. Patients undergoing radiotherapy alone had a better outcome if the baseline SUVmax in the primary tumor was lower $(\leq 6.6)$, whereas in the combined chemoradiation therapy group a higher baseline SUV tended to correlate with better outcome, possibly reflecting the better efficacy of chemotherapy in tumor tissue with a higher rate of cellular proliferation. The other recent study on the utility of ${ }^{18}$ F-FLT PET during radiation therapy was reported by Kishino et al. in the October 2012 issue of The Journal of Nuclear Medicine (6). Different from the study by Hoeben et al., the follow-up ${ }^{18}$ F-FLT PET scans in the study by Kishino et al. (6) were obtained at a later time point during treatment (median of 40 Gy of radiotherapy). The image analysis also differed in the study by Kishino et al., which dichotomized the results as positive or negative based on visual assessment of residual uptake rather than the change in SUV. This study found that during radiotherapy ${ }^{18}$ F-FLT uptake in the tumor disappeared faster than ${ }^{18} \mathrm{~F}-\mathrm{FDG}$; however, the residual ${ }^{18} \mathrm{~F}$-FLT uptake after $40 \mathrm{~Gy}$ of therapy still only showed a positive predictive value of $35 \%$ (17\% for ${ }^{18} \mathrm{~F}$ FDG). The negative predictive value of absence of uptake was similar for ${ }^{18} \mathrm{~F}$ FLT and ${ }^{18}$ F-FDG (97\% and $100 \%$, respectively), although many more lesions showed visual disappearance of ${ }^{18}$ F-FLT accumulation at $40 \mathrm{~Gy}$. The presence of residual ${ }^{18} \mathrm{~F}$-FLT or ${ }^{18} \mathrm{~F}$-FDG uptake after 40 Gy of radiation did not correlate with local control of disease over a median follow-up of 39 mo.

Several preliminary conclusions can be drawn from these studies. (1) Head and neck cancer treatment monitoring during radiotherapy with $\mathrm{PET}$, either with ${ }^{18} \mathrm{~F}$-FDG or ${ }^{18} \mathrm{~F}$-FLT, is more effective if done earlier during therapy rather than later, probably at around 20 Gy ( 2 wk with the conventional fractionation of $2 \mathrm{~Gy} / \mathrm{d}$ ). This may be at least partly explained by the inability of PET scans obtained later during the course of therapy to identify microscopic residual disease that is ultimately responsible for tumor recurrence. As shown by Kasamon et al. in lymphoma, the late PET scan may not be able to differentiate the tumors with the higher rate of cell kill from tumors with slower cell kill (18), leading to a false-negative late PET scan because microscopic residual disease will be below the detectability of the PET imaging system. In early responding tumors on the other hand, the rapid cell kill will lead to a rapid and significant drop in uptake of ${ }^{18}$ F-FLT and ${ }^{18}$ F-FDG early after initiation of radiotherapy. Another potential issue is the development of postradiation inflammatory changes, which will become more profound later in the therapy and may confound the interpretation of PET images. (2) Accurate quantitation of uptake in addition to visual assessment appears to improve the predictive value of PET in monitoring response to radiation therapy in head and neck cancer. This requires careful standardization of PET acquisition and image analysis for larger multicenter studies that can validate the utility of PET in monitoring response to radiation therapy in head and neck cancers. (3) Comparison data of ${ }^{18} \mathrm{~F}-\mathrm{FLT}$ and ${ }^{18} \mathrm{~F}$-FDG PET imaging during radiotherapy of head and neck cancer is limited. Compared with ${ }^{18} \mathrm{~F}-\mathrm{FDG}$, the more rapid change in ${ }^{18} \mathrm{~F}-\mathrm{FLT}$ uptake during therapy may suggest that ${ }^{18} \mathrm{~F}$ FLT better reflects the change in tumor biology with radiation; however, outcome data demonstrating the superiority of ${ }^{18} \mathrm{~F}$ FLT to ${ }^{18}$ F-FDG in this setting are still lacking. It may be prudent to incorporate ${ }^{18} \mathrm{~F}-\mathrm{FDG}$ PET in future clinical trials evaluating the utility of ${ }^{18}$ F-FLT PET during radiotherapy to monitor treatment response in head and neck cancers.

\section{Yusuf Menda \\ John M. Buatti}

University of Iowa Carver College of

Medicine

Iowa City, Iowa

\section{REFERENCES}

1. Parkin DM, Bray F, Ferlay J, Pisani P. Global cancer statistics, 2002. CA Cancer J Clin. 2005;55:74-108.
2. Siegel R, Naishadham D, Jemal A. Cancer statistics, 2013. CA Cancer J Clin. 2013;63:11-30.

3. National Comprehensive Cancer Network. Head and Neck Cancers. Version 1.2012. NCCN Clinical Practice Guidelines in Oncology (NCCN Guidelines). Available at: http://www.nccn.org/professionals/ physician_gls/pdf/head-and-neck.pdf. Accessed March 12, 2013.

4. Brun E, Kjellen E, Tennvall J, et al. FDG PET studies during treatment: prediction of therapy outcome in head and neck squamous cell carcinoma. Head Neck. 2002;24:127-135.

5. Hentschel M, Appold S, Schreiber A, et al. Early FDG PET at 10 or 20 Gy under chemoradiotherapy is prognostic for locoregional control and overall survival in patients with head and neck cancer. Eur J Nucl Med Mol Imaging. 2011;38:1203-1211.

6. Kishino T, Hoshikawa H, Nishiyama $\mathrm{Y}$, Yamamoto Y, Mori N. Usefulness of 3'-deoxy$3^{\prime}{ }^{18}$ F-fluorothymidine PET for predicting early response to chemoradiotherapy in head and neck cancer. J Nucl Med. 2012;53:1521-1527.

7. Ceulemans G, Voordeckers M, Farrag A, Verdries D, Storme G, Everaert H. Can 18-FDG-PET during radiotherapy replace post-therapy scanning for detection/ demonstration of tumor response in head-and-neck cancer? Int J Radiat Oncol Biol Phys. 2011;81:938942.

8. Bruechner K, Bergmann R, Santiago A, et al. Comparison of $\left[{ }^{18} \mathrm{~F}\right] \mathrm{FDG}$ uptake and distribution with hypoxia and proliferation in $\mathrm{FaDu}$ human squamous cell carcinoma (hSCC) xenografts after single dose irradiation. Int J Radiat Biol. 2009;85:772-780.

9. Rasey JS, Grierson JR, Wiens LW, Kolb PD, Schwartz JL. Validation of FLT uptake as a measure of thymidine kinase-1 activity in A549 carcinoma cells. J Nucl Med. 2002;43:1210-1217.

10. Cobben DC, van der Laan BF, Maas B, et al. ${ }^{18} \mathrm{~F}-$ FLT PET for visualization of laryngeal cancer: comparison with ${ }^{18}$ F-FDG PET. J Nucl Med. 2004;45:226-231.

11. Hoshikawa H, Kishino T, Mori T, et al. Comparison of ${ }^{18}$ F-FLT PET and ${ }^{18}$ F-FDG PET for detection of cervical lymph node metastases in head and neck cancers. Acta Otolaryngol. 2012;132:1347-1354.

12. Hoshikawa H, Nishiyama Y, Kishino T, Yamamoto Y, Haba R, Mori N. Comparison of FLT-PET and FDGPET for visualization of head and neck squamous cell cancers. Mol Imaging Biol. 2011;13:172-177.

13. Linecker A, Kermer C, Sulzbacher I, et al. Uptake of ${ }^{18} \mathrm{~F}$-FLT and ${ }^{18} \mathrm{~F}$-FDG in primary head and neck cancer correlates with survival. Nuklearmedizin. 2008;47:80-85.

14. Menda Y, Boles Ponto LL, Dornfeld KJ, et al. Kinetic analysis of $3^{\prime}$-deoxy- $3^{\prime}-{ }^{18} \mathrm{~F}$-fluorothymidine $\left({ }^{18} \mathrm{~F}\right.$ FLT) in head and neck cancer patients before and early after initiation of chemoradiation therapy. J Nucl Med. 2009;50:1028-1035.

15. Troost EG, Vogel WV, Merkx MA, et al. ${ }^{18}$ F-FLT PET does not discriminate between reactive and metastatic lymph nodes in primary head and neck cancer patients. J Nucl Med. 2007;48:726-735.

16. Troost EG, Bussink J, Hoffmann AL, Boerman OC, Oyen WJ, Kaanders JH. ${ }^{18}$ F-FLT PET/CT for early response monitoring and dose escalation in oropharyngeal tumors. J Nucl Med. 2010;51:866-874.

17. Hoeben BA, Troost EG, Span PN, et al. 18F-FLT PET during radiotherapy or chemoradiotherapy in head and neck squamous cell carcinoma is an early predictor of outcome. J Nucl Med. 2013;54: 532-540.

18. Kasamon YL, Jones RJ, Wahl RL. Integrating PET and PET/CT into the risk-adapted therapy of lymphoma. J Nucl Med. 2007;48(suppl 1):19S-27S. 